\title{
Sensory descriptors of cocoa beans from cultivated trees of Soconusco, Chiapas, Mexico
}

\author{
Alfredo VÁZQUEZ-OVANDO ${ }^{1}$, Lisbeth CHACÓN-MARTÍNEZ ${ }^{1}$, David BETANCUR-ANCONA², \\ Héctor ESCALONA-BUENDÍA³, Miguel SALVADOR-FIGUEROA ${ }^{1 *}$
}

\begin{abstract}
The odor and taste profile of cocoa bean samples obtained from trees cultivated in southern Mexico were evaluated by trained panelists. Seven representative samples (groups) of a total of 45 were analyzed. Four attributes of taste (sweetness, bitterness, acidity and astringency), and nine of odor (chocolate, nutty, hazelnut, sweet, acidity, roasted, spicy, musty and off-odor) were evaluated. A sample (G7) with higher scores in sweet taste and sweet and nutty odors was detected, as well as a high association between these descriptors and the sample, analyzed through principal component analysis (PCA). Similarly, samples that showed high scores for non-desired odors in cocoas such as off-odor and musty were identified and related by PCA to roasted odor and astringent taste (G2 and G4). Based on this scores, the samples were listed in descending order by their sensory quality as $\mathrm{G} 7>\mathrm{G} 5>\mathrm{G} 6>\mathrm{G} 3>\mathrm{G} 1>\mathrm{G} 4>\mathrm{G} 2$.
\end{abstract}

Keywords: quantitative descriptive analysis; Criollo cocoa; chocolate odor; spicy odor.

Practical Application: Descriptors generated are useful for characterizing the sensory quality of cocoa grown in southern Mexico.

\section{Introduction}

From its origin as a spicy frothy drink (Coe \& Coe, 2007) or fermented beverage prepared by several peoples that lived in Mesoamerica nearly 4,000 years ago (Crown, 2013), chocolate has evolved into one of the non-basic food products of highest popularity and acceptance especially in Western countries. Its texture, the sensory stimuli of pleasure and mood produced by its consumption (Macht \& Dettmer, 2006), in addition to the amount and composition of its phenolic compounds which provide health benefits, are the main reasons for its acceptance (Djoussé et al., 2011; d'El-Rei et al., 2013).

The main raw materials for the production of chocolate are dried cocoa beans, which are derived from the cocoa tree (Theobroma cacao L.). In 2012, > 5 million tons of dry beans were produced in tropical regions of the world (Food and Agriculture Organization, 2013). About $65 \%$ of the beans are obtained from trees grown in Africa, but only those obtained from trees grown in some parts of the Americas are considered of the highest quality due to the sensory characteristics they possess and conserve from Criollo parents (Smith, 1999). These characteristics which have a direct impact on the quality of chocolate are due to genetic, environmental and post harvest processing factors (Voight, 2013). The first determining factor associated with the beans obtained from the Criollo variety is genetic. This variety was domesticated by the peoples of Mesoamerica (Cruz et al., 1995) and there are reports of the existence of trees with high ancestry in several countries which once formed that region (Motilal et al., 2010; Trognitz et al., 2011; Vázquez-Ovando et al., 2014). Similarly, the environmental factor depends on the farm region and it has been reported to exert a strong effect on the chemical characteristics and consequently on the sensory properties exhibited by beans (Afoakwa et al., 2008). Post harvest processing also influences the final quality of beans. An inefficient management (untimely cutting of fruits, non-fermentation, prolonged fermentation, improper drying, among others) may reduce quality (Afoakwa et al., 2008). If post harvest practices remain constant, it can be assumed that genetic and edapho-climatic conditions where the trees grow determines the quality of cocoa. As a result of these processes, it has been shown that cocoa grown in certain regions of the world possess very specific sensory characteristics (Sukha et al., 2008).

In the southeast region of Mexico, the history of cocoa farming dates back to pre-colonial times, when it was used even as currency by the Aztec people and their tributaries. This fact shows the importance that cocoa had (Crown, 2013). The Criollo variety was cultivated by the Olmecs, Mayas, Mokayas and others peoples as recorded in several codices. In the mid-twentieth century, genotypes of greater production were introduced in the region, which when recombined with native plantations gave rise to the trees cultivated at present. The differentiated genetic and chemical characteristics of these trees suggest that sensory characteristics may also be particular. Some specialized industrialists from various European countries have shown specific interest in cocoa obtained from plantations in the Soconusco region, in southern Mexico. However, there are no sensory descriptors to characterize such quality. Therefore, the aim of this work was to obtain sensory descriptors for taste and odor of cocoa beans from trees cultivated in Soconusco, Mexico, with the participation of trained panelists. 


\section{Materials and methods}

\subsection{Collection and processing of samples}

Fruits (2-6 per tree) were collected from 45 cocoa trees in seven municipalities (Suchiate, SUED; Frontera Hidalgo, FHSA; Cacahoatán, CAAM; Tapachula, TASG; Mazatán, MAMG; Huehuetán, HUJF, HUTG and Tuzantán, TUCA, TURA, TCHR) in the Soconusco region of Chiapas State in Mexico. The selection was based on phenotypic traits described by Engels (1983) for the Criollo variety (sweet pulp, white beans, elongated pods with pronounced grooves) and high sensory quality (declared by cocoa farmers). The fruits were harvested at consumption ripening (yellowing of more than $60 \%$ of the pod), labeled, transported to the laboratory in polyethylene bags and processed the same day. In the laboratory, the pods were washed in clean water and sanitized surface (70\% ethanol) and placed in a laminar flow hood. Using a sanitized scalpel, each pod was hand dissected from the middle (equatorial), the two sections were separated carefully and the seed were freedom of the surrounding. The connecting thread (placenta) was removed; the seed and pulp were reintroduced in the pod: The re-armed pod was sealed with tape Millipore ${ }^{\circledast}$ (Vázquez-Ovando et al., 2015). Then the pods were placed vertically in an acclimation chamber and maintained at $28{ }^{\circ} \mathrm{C}$ and $\mathrm{RH}$ of $80 \%$ for a period of six days (to ensure the full fermentation in the fruit with more pulp content), reversing their position every $24 \mathrm{~h}$. Once micro-fermentation was completed, the beans were dried at $60{ }^{\circ} \mathrm{C}$ for 48 hours in a forced air oven (Felisa ${ }^{\bowtie}$ Mexico). The dried beans were stored under refrigeration $\left(4^{\circ} \mathrm{C}\right)$ in sealed glass jars until the day of sensory evaluation.

\subsection{Grouping of samples prior to sensory evaluation}

In order to obtain enough samples that would allow panelists to carry out the sensory evaluation in just one session, the 45 samples were grouped using multivariate analysis (principal component analysis [PCA] and discriminant analysis [DA]) of morphological and chemical characteristics of the beans (Vázquez-Ovando et al., 2015). Derived from this analysis, seven groups were formed with a minimum of two and up to nine samples per group. The groups were previously reported by Vázquez-Ovando et al. (2015). The average chemical compositions of the groups are shown in Table 1. Composite samples (groups) were formed after mixing all samples belonging to the same group. A representative sample from each group was taken to be evaluated by the trained panelists.

\subsection{Selection and training of panelists}

Based on procedures of descriptive analysis (QDA method, Lawless \& Heymann, 1999), personal invitations were issued to 40 undergraduate students (between the ages of 20 and $23 \mathrm{y}$ ) in order to pre-select panelists. The pre-selection questionnaire was administered to assess health status, eating habits and the ability of panelists to express the taste sensations caused by tasting a derivative of cocoa. The screening criteria included good health (self report), non-smoker, ability to work well on a panel, interest in participating, a consumer of cocoa or its derivatives or at least did not dislike its consumption, no allergic reactions to consumption of cocoa and its derivatives, and most importantly the skills to describe and express the sensations perceived.

Table 1. Classification of 45 samples into seven groups based on the multivariate analysis of chemical parameters of cocoa beans. The value of parameters is a mean and standard deviation of number $(n=2$ to 9$)$ of samples belonging to this group. Made with data reported by Vázquez-Ovando et al. (2015).

\begin{tabular}{|c|c|c|c|c|c|c|c|c|}
\hline \multicolumn{2}{|c|}{ Group } & G1 & G2 & G3 & G4 & G5 & G6 & G7 \\
\hline \multirow{9}{*}{\multicolumn{2}{|c|}{ Parameter }} & TASG07 & TASG08 & TASG09 & CAAM07 & FHSA05 & TASG10 & MAMG03 \\
\hline & & CAAM09 & TASG13 & TASG12 & CAAM14 & SUED05 & SUED03 & HUTG04 \\
\hline & & MAMG11 & TASG23 & TASG15 & FHSA03 & MAMG01 & SUED06 & \\
\hline & & HUTG03 & CAAM01 & TASG16 & FHSA04 & MAMG04 & MAMG02 & \\
\hline & & TURA01 & CAAM06 & TASG17 & FHSA06 & HUJF05 & MAMG05 & \\
\hline & & MAMG13 & CAAM08 & TASG21 & SUED01 & HUJF06 & MAMG08 & \\
\hline & & & CAAM11 & MAMG06 & TUCA02 & & MAMG10 & \\
\hline & & & & TCHR05 & HUJF04 & & & \\
\hline & & & & & MAMG14 & & & \\
\hline \multicolumn{2}{|c|}{ Moisture (g.100g $\left.\mathrm{g}^{-1}\right)$} & $4.46 \pm 1.20$ & $4.02 \pm 0.90$ & $3.39 \pm 1.51$ & $4.36 \pm 1.61$ & $5.30 \pm 0.78$ & $3.56 \pm 1.54$ & $3.00 \pm 1.13$ \\
\hline \multicolumn{2}{|c|}{ Ash $\left(\mathrm{g} .100 \mathrm{~g}^{-1} \mathrm{db}\right)$} & $4.69 \pm 0.94$ & $4.33 \pm 1.59$ & $4.45 \pm 0.79$ & $4.72 \pm 1.06$ & $4.42 \pm 0.95$ & $5.58 \pm 0.78$ & $5.84 \pm 2.33$ \\
\hline \multicolumn{2}{|c|}{ Fat $\left(\mathrm{g} .100 \mathrm{~g}^{-1} \mathrm{db}\right)$} & $45.89 \pm 3.70$ & $46.38 \pm 8.52$ & $48.32 \pm 7.40$ & $46.31 \pm 4.31$ & $51.50 \pm 3.07$ & $46.66 \pm 4.81$ & $40.12 \pm 6.48$ \\
\hline \multicolumn{2}{|c|}{ Protein $\left(\mathrm{g} .100 \mathrm{~g}^{-1} \mathrm{db}\right)$} & $13.48 \pm 1.25$ & $12.63 \pm 0.87$ & $12.64 \pm 1.48$ & $13.85 \pm 1.44$ & $13.22 \pm 1.19$ & $12.72 \pm 1.26$ & $17.25 \pm 1.82$ \\
\hline \multicolumn{2}{|c|}{$\begin{array}{l}\text { Polyphenols (g } \\
\text { GAE. } 100 \mathrm{~g}^{-1} \mathrm{db} \text { ) }\end{array}$} & $2.63 \pm 0.23$ & $3.02 \pm 0.45$ & $4.16 \pm 0.21$ & $5.65 \pm 0.58$ & $3.35 \pm 0.30$ & $1.88 \pm 0.46$ & $0.96 \pm 0.41$ \\
\hline \multirow{8}{*}{$\begin{array}{l}\text { Fatty acids } \\
\text { (\% db of } \\
\text { total fatty } \\
\text { acid) }\end{array}$} & $\mathrm{C} 14: 0$ & $0.10 \pm 0.03$ & $0.08 \pm 0.03$ & $0.19 \pm 0.19$ & $0.18 \pm 0.25$ & $0.21 \pm 0.17$ & $0.08 \pm 0.02$ & $0.09 \pm 0.00$ \\
\hline & $\mathrm{C} 16: 1$ & $0.18 \pm 0.04$ & $0.14 \pm 0.03$ & $0.15 \pm 0.05$ & $0.21 \pm 0.04$ & $0.23 \pm 0.05$ & $0.15 \pm 0.04$ & $0.31 \pm 0.00$ \\
\hline & $\mathrm{C} 16: 0$ & $25.70 \pm 2.36$ & $20.53 \pm 2.94$ & $21.89 \pm 2.39$ & $24.24 \pm 2.10$ & $26.27 \pm 2.35$ & $23.77 \pm 1.35$ & $28.48 \pm 0.69$ \\
\hline & C18:2 & $2.14 \pm 0.46$ & $1.88 \pm 0.52$ & $1.79 \pm 0.62$ & $1.40 \pm 0.81$ & $1.35 \pm 0.82$ & $1.22 \pm 0.60$ & $1.54 \pm 0.03$ \\
\hline & C18:1 & $32.03 \pm 2.54$ & $30.11 \pm 1.83$ & $29.59 \pm 2.58$ & $32.23 \pm 0.93$ & $33.23 \pm 2.45$ & $32.85 \pm 1.34$ & $32.76 \pm 1.98$ \\
\hline & C18:0 & $37.85 \pm 2.26$ & $45.79 \pm 3.00$ & $44.88 \pm 3.77$ & $39.91 \pm 1.64$ & $36.97 \pm 2.43$ & $40.50 \pm 1.71$ & $35.19 \pm 1.84$ \\
\hline & C20:0 & $1.04 \pm 0.35$ & $1.14 \pm 0.18$ & $1.11 \pm 0.25$ & $1.02 \pm 0.15$ & $1.10 \pm 0.10$ & $1.16 \pm 0.22$ & $1.30 \pm 0.28$ \\
\hline & C22:0 & $0.96 \pm 0.39$ & $0.33 \pm 0.21$ & $0.40 \pm 0.25$ & $0.43 \pm 0.21$ & $0.25 \pm 0.11$ & $0.26 \pm 0.13$ & $0.33 \pm 0.24$ \\
\hline
\end{tabular}


A meeting was held with the screening panelists (25 people) to explain the aim of the study, its importance, scope and level of commitment. Subsequently, detection tests were carried out to familiarize panelists with characteristic descriptors of taste, using solutions with concentrations of $12 \mathrm{~g} \cdot \mathrm{L}^{-1}$ sucrose (sweet), 0.27 g. $\mathrm{L}^{-1}$ of caffeine (bitter), 0.6 g. $\mathrm{L}^{-1}$ citric acid (acidity), $2 \mathrm{gL}^{-1}$ sodium chloride (salty) and $0.5 \mathrm{~g} . \mathrm{L}^{-1}$ tannic acid for the astringent attribute (International Organization for Standards, 1993). Stimulus perception tests were performed by each of the panelists, and a candidate was considered acceptable when correct in $100 \%$ of the tests. Subsequently, ordering tests were performed using the concentrations shown in Table 2. Panelists were trained in sessions of $2 \mathrm{~h}$ per week for a period of 22 weeks by ordering tests. For variables of taste, it was verified that the panelists had the ability to detect differences and order concentrations properly. Panelists were presented with a series of four concentrations for each stimulus in a circular order and requested to order them from lowest to highest concentration. During the first sessions standard solutions (Table 2) were used, and later cocoa bean samples were presented to familiarize the panelists with their taste.

Similarly, the selected panelists were trained to associate descriptions of specific odors for cocoa beans, either by previous experience or references provided (cocoa powder, cocoa paste, dried and roasted cocoa beans) so that all panelists agreed on the same sensory language. Nine odor descriptors were considered: chocolate, nutty, hazelnut, acidity, sweet, spicy, roasted, and the auxiliary descriptors associated with a defective sample as musty odor and off-odor. The data generated by panelist and attribute (or stimulus) were subjected to analysis of variance and eight panelists ( 5 women and 3 men) were chosen on the basis of their discriminative capacity $(\mathrm{p}<0.30)$ and repeatability $(\mathrm{p}>0.05)$ as suggested by Melo et al. (2009).

\subsection{Sample preparation and sensory evaluation}

Prior to the evaluation, $300 \mathrm{~g}$ of beans from each group (composite sample) were roasted on an electric hot plate $\left(150^{\circ} \mathrm{C}\right.$ for $15 \mathrm{~min}$ ) and the rind was removed at the end of the process.

Table 2. Materials and concentrations of aqueous solutions used in training tests for panelists (International Organization for Standards, 1993).

\begin{tabular}{lll}
\hline \multicolumn{1}{c}{ Taste } & \multicolumn{1}{c}{ Material } & \multicolumn{1}{c}{ Concentration $\left(\mathrm{g} . \mathrm{L}^{-1}\right)$} \\
\hline Sweet & Sucrose & $0.025,0.25,1.25,2.5$ \\
Astringency & Tannic acid & $0.05,0.08,0.125,0.25$ \\
Acidity & Tartaric acid & $0.025,0.037,0.055,0.085$ \\
Bitter & Caffeine & $0.037,0.055,0.085,0.127$ \\
\hline
\end{tabular}

$0.5 \mathrm{~g}$ of roasted beans were placed in plastic containers of $15 \mathrm{~cm}^{3}$. A total of 168 containers for odor testing and 168 for taste were prepared. The containers were sealed and left for $6 \mathrm{~h}$ at a temperature of $28^{\circ} \mathrm{C}$ to promote the accumulation of volatiles. The final evaluation was conducted in a single session in a spacious, enclosed area with adequate lighting and a temperature of $25^{\circ} \mathrm{C}$. Containers coded with three digits were presented to panelists. First, odor testing was performed, for which a series of seven containers arranged in a circle were presented to the panelist. Each of the panelists was asked to remove the lid of the sealed container, inhale the volatiles and cast their judgment; to this end each panelist was given seven pages (one for each sample) in which they were asked to mark on an unstructured linear scale of $90 \mathrm{~mm}$ the stimulus perceived for each of the attributes (one line per attribute). This procedure was conducted two more times (in triplicate) using codes of three different digits (21 different combinations) for each sample and repetition. Similarly, panelists were asked to evaluate the samples for the four predefined attributes of taste (Lawless \& Heymann, 1999). For this evaluation, the panelists were asked to rinse their mouth with water between samples. When required, the panelists used tea bags to desaturate their olfactory system or flavourless biscuits to desaturate taste.

\subsection{Data analysis}

Distances were measured at the origin of the mark where the panelist evaluated the attribute and the corresponding values were recorded for each of the descriptors $(\mathrm{cm})$. Considering the data as continuous variables, an analysis of variance was performed. The means were classed by the Newman-Keuls test at 5\% limit (Assemat et al., 2005).

With data from all descriptors (a total of 13), a principal component analysis (PCA) was carried out, and with the graphic representation of the components that most explained the variation, the correlation between descriptors and samples was established (Thamke et al., 2009). All statistical analyses were carried out using XLSTAT Software (version 2013.2.07 Addinsoft $^{\text {tm }}$ SARL).

\section{Results and discussion}

For the four attributes of taste, a significant difference was found in at least one sample (Table 3). It may be noted that the attributes of acidity and bitterness presented higher values than sweetness. The lowest value of sweetness (0.39) was found for sample G5. It has been reported that the compounds present in cocoa beans contributing to sweet taste (monosaccharides, disaccharides, oligosaccharides and some L-amino acids) are in a concentration lower than the perception threshold of a panelist (Stark et al., 2006); this may indicate that the samples analyzed

Table 3. Means value of descriptors of taste obtained by trained panelists from seven cocoa samples (representing 45 samples).

\begin{tabular}{|c|c|c|c|c|c|c|c|}
\hline Attribute & G1 & G2 & G3 & G4 & G5 & G6 & G7 \\
\hline Sweet & $1.19^{\mathrm{bcd}}$ & $1.43^{\mathrm{bc}}$ & $1.70^{\mathrm{b}}$ & $0.75^{\mathrm{cd}}$ & $0.39^{\mathrm{d}}$ & $1.08^{\mathrm{bcd}}$ & $2.83^{\mathrm{a}}$ \\
\hline Bitter & $4.19^{\mathrm{ab}}$ & $3.34^{\mathrm{bc}}$ & $3.07^{c}$ & $4.66^{\mathrm{a}}$ & $3.82^{\mathrm{abc}}$ & $3.76^{\mathrm{abc}}$ & $3.23^{b c}$ \\
\hline Acidity & $2.32^{\mathrm{ab}}$ & $3.09^{\mathrm{a}}$ & $2.90^{\mathrm{a}}$ & $2.87^{\mathrm{a}}$ & $1.59^{b c}$ & $1.37^{\mathrm{c}}$ & $1.23^{\mathrm{c}}$ \\
\hline Astringent & $0.96^{\mathrm{b}}$ & $1.75^{\mathrm{ab}}$ & $1.21^{\mathrm{b}}$ & $1.93^{\mathrm{ab}}$ & $0.98^{\mathrm{b}}$ & $2.28^{\mathrm{a}}$ & $1.42^{\mathrm{ab}}$ \\
\hline
\end{tabular}

Values with the same letter by row do not differ significantly $(\mathrm{p}>0.05)$. Values were obtained in $9 \mathrm{~cm}$ unstructured line. 
could have had a concentration above the threshold mainly of sucrose, which is reported to be the sugar contributing the most to this attribute. Regarding the bitter taste, the G4 sample had the highest score and was significantly different $(\mathrm{p}<0.05)$ from other samples. The bitter taste of cocoa beans is mainly due to the alkaloids present, although not exclusively, since molecules such as diketopiperazines, free L-amino acids or peptides also contribute to the perception of bitterness, as proven by Stark et al. (2006). Other molecules that may also contribute to the perception of bitterness, not directly but rather as a "bitter-astringent" sensation, are low molecular weight tannins such as epicatechins, catechins and procyanidins, and that together as total polyphenols, are in high concentrations in G4 (Table 1). However, the PCA (Figure 1) indicated that the astringent and bitter taste were not correlated and conversely a stronger association was observed between the acid and astringent tastes. This may explain why the results of this study do not coincide with the order reported by Stark et al. (2006) in samples of cocoa (bitter > astringent > sour), or perhaps something similar to that proposed happens with sweet taste, i.e. the contents of organic acids (lactic, citric, succinic, acetic, malic) are found in higher amounts than in cocoa at other latitudes and have a determining impact on this attribute. This has already been reported for cocoa in several regions of the world, where panelists have given scores for acidity even higher than those of bitterness (Jinap et al., 1995).

Figure 2 shows the odor profile of each sample evaluated by the panel. Significant differences among samples $(p<0.05)$ were found for the nutty, sweet, musty and off-odor attributes. The highest score of chocolate odor (2.48) was found in the G1 sample, but since there was no difference between samples ( $p>0.05$ ) only in the G3, G5 and G6 samples was a correlation between chocolate and hazelnut odors found by the PCA analysis (Figure 1). Some aldehydes, ketones and pyrazines which are formed during fermentation and roasting partially contribute to chocolate odor (Rodriguez-Campos et al., 2011).

In general terms, the highest scores were found for the sweet and nutty odors. Particularly for the sweet odor, the G7 sample had a score of 3.39. According to Afoakwa et al. (2009) this odor is associated with molecules such as alcohols, ketones, aldehydes, esters and pyrazines, which are highly desirable in cocoa beans, as they contribute to the high quality of chocolates. These compounds are formed from precursor molecules during fermentation and are further enhanced in roasting (Frauendorfer \& Schieberle, 2008). The cocoas from the Mazatán location (code MAMG, Table 1) were found to have the highest values of sweet odor which may be related to the fruit pulp content, since upon opening the pods it was noted that the samples from this region contained a remarkably higher content of pulp surrounding the beans. The high content of pulp probably increased the sugar content that can be transformed to molecules which contribute to the sweet odor or serve as a cultivation means that may enhance the multiplication of microorganisms responsible for making those changes (Quesnel, 1965).

For attributes where a significant difference was found, the G2 sample showed the highest values for musty (1.89) and off-odor (2.48). The same sample was correlated with the acidity, acidity odor, astringency, roasted odor and off odor attributes (Figure 1). The presence of undesirable odors such as musty (1.89) and off-odor are indicators of inappropriate post-harvest handling, in this sense the amount of mucilage in pods may have determined
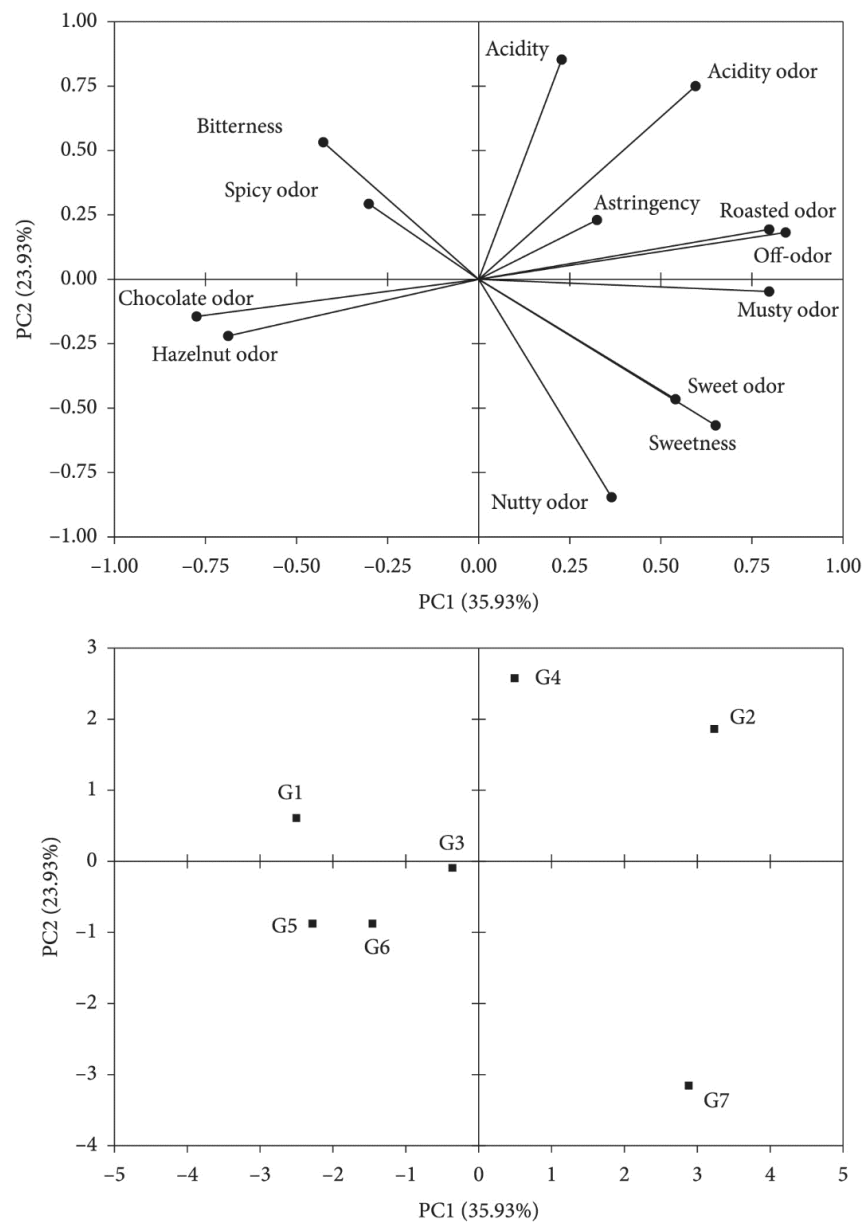

Figure 1. Principal component analysis (PCA) loadings for descriptors (up) and cocoa samples (down).

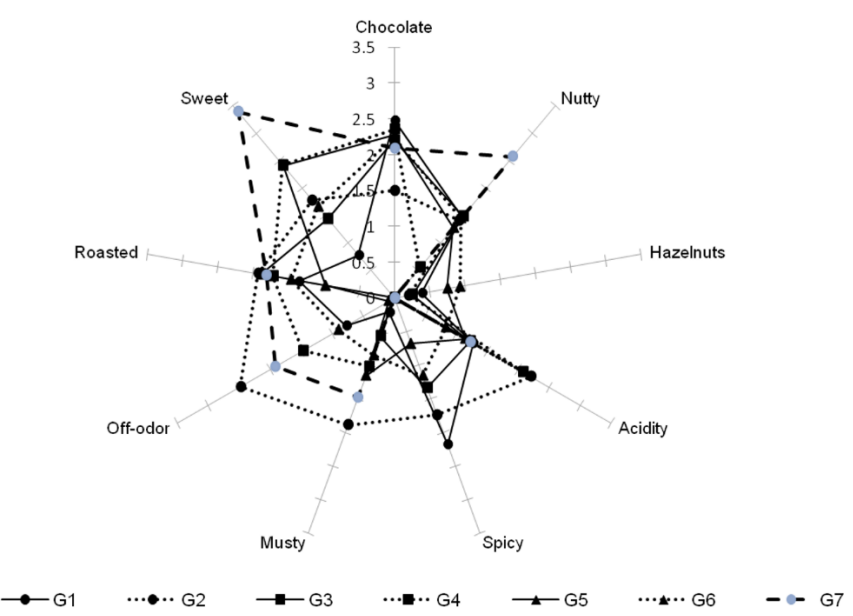

Figure 2. Attributes of odor described for seven samples of fermented cocoa obtained from plants cultivated in the southern region of Mexico (representing 45 samples). 
the presence of these odors. García-Alamilla et al. (2007) have reported that upon the exhaustion of the sugars and water from the fermentation medium (basically the mucilage content in the sample), the formation of acetic, propionic, isobutyric and isovaleric acids begin. These acids are associated with the occurrence of undesired odors such as rancidity, fat, and cheese in cocoa, which were detected and described as off-odor

The presence of the spicy descriptor detected by panelists may be related to the presence of molecules as dihydrocapsaicin, norhydrocapsaicin, homocapsaicin, carotenoids, flavonols, all of phenolic nature (Serra-Bonvehí, 2005). The content of phenolic compounds was significant in the analyzed samples (Table 1). The strong correlation found between bitterness and spicy odors also supports this hypothesis since the contribution of polyphenols to bitterness was inferred before (Figure 1). The use of the spicy descriptor may also be associated with local terminology, since the region has chili of the genus Capsicum sp. called "chile chocolate" in Spanish and panelists accustomed to this smell created the descriptor and associated it with the powder of this chili.

Unlike other studies (Sukha \& Butler, 2005) which set out descriptors of flower and fruit aromas, in this study the panelists did not perceive, and therefore did not propose, such descriptors. Conversely, predominant in all samples were the chocolate, spicy, hazelnut, acidity and roasting odors, which may be used as the characteristics that identify cocoas from this part of Mexico (Soconusco). Only for some samples was a positive correlation found between the content of polyphenols and the astringent taste, i.e. samples where the polyphenol content and the scores for the astringent taste were higher. The same happened with bitter taste. This is contrary to what has been reported (Crozier et al., 2011), since positive correlations have been found between polyphenol content and astringent taste. This lack of total correlation may be explained by the fact that in some samples, roasting promoted greater oxidation of phenolic compounds (quantified in unfermented seeds), consequently greater formation of quinones derived from some polyphenols such as catechins, epicatechins, and condensation of proteins, resulting in reduced astringency and bitter taste (Forsyth \& Quesnel, 1957).

Based on the results, the samples considered with higher sensory quality are G7 with lower acidity (1.23), higher sweet taste (2.83) and sweet odor (3.39) and less bitter taste (3.23); the G3 sample where undesirable odors were absent and which had low astringent taste (1.21); and the G1 sample showed higher chocolate (2.48), chili (2.18) and roasted (1.35) odors. However, only the first two samples (G7 and G3) were found to be correlated (Figure 1) with desirable descriptors in quality samples (sweetness, chocolate, nuts, hazelnuts), together with the G5 and G6 samples. At the other extreme, the samples found with low sensory quality were G2 and G4, which despite having some desirable odors, in general they had high values of acidity, off-odor and musty. From the above it can be established that the sensory quality of cocoas may be defined as G7> G5> G6>G3> G1> G4> G2 .

The results indicate a low contribution from the environment, since samples with similar codes came from the same collection site but were sensorially different. The results from the chemical composition analyses of these beans performed in our group support this hypothesis. Since the post-harvest processing was the same for all samples, the only variable that explains the differentiation is allelic composition. It has been demonstrated that cocoas included in this study have little Criollo ancestry, i.e. a group not genetically corresponding to the old Criollo cultivated by the Mayas in Mesoamerica (Vázquez-Ovando et al., 2014). Possibly we are dealing with a genetic group in a process of adapting to the conditions of Soconusco that has boosted its own odor and taste attributes, which as noted earlier, are of interest for international markets.

\section{Conclusions}

The cacaos of the region of Soconusco, Mexico have sensory characteristics unique to and different from cocoa cultivated in other world regions. No descriptors were identified that associated with flower and fruit odor as in other cacao types. We achieved differentiated samples (groups) of high and low sensory quality. The highest sensory quality cocoas were associated with descriptors of sweet taste, less bitterness and chocolate and hazelnut odors. Conversely, the low quality cocoas were associated with bitter taste and off-odors. The spicy-odor descriptor is reported for the first time for samples of cocoa beans.

\section{Acknowledgements}

The first author extends thanks to the Posgrado en Ciencias Biológicas of the Universidad Nacional Autónoma de México (UNAM), for the academic instruction in doctoral studies. To the Consejo Nacional de Ciencia y Tecnología (CONACyT, Mexico) for a financial grant awarded to the first author. The authors also thank the efforts of the sensory panelists involved this study.

\section{References}

Afoakwa, E. O., Paterson, A., Fowler, M., \& Ryan, A. (2008). Flavor formation and character in cocoa and chocolate: a critical review. Critical Reviews in Food Science and Nutrition, 48(9), 840-857. http:// dx.doi.org/10.1080/10408390701719272. PMid:18788009

Afoakwa, E., Paterson, A., Fowler, M., \& Ryan, A. (2009). Matrix effects on flavour volatiles release in dark chocolates varying in particle size distribution and fat content using GC-mass spectrometry and GC-olfactometry. Food Chemistry, 113(1), 208-215. http://dx.doi. org/10.1016/j.foodchem.2008.07.088.

Assemat, S., Lachenaud, P., Ribeyre, F., Davrieux, F., Pradon, J. L., \& Cros, E. (2005). Bean quality traits and sensory evaluation of wild Guianan cocoa populations (Theobroma cacao L.). Genetic Resources and Crop Evolution, 52(7), 911-917. http://dx.doi.org/10.1007/ s10722-003-6117-2.

Coe, S. D., \& Coe, M. D. (2007). The true history of chocolate (2nd. ed.). New York: Thames and Hudson.

Crown, P. L. (2013). Prehispanic use of cacao. In R. Watson, V. R. Preedy \& S. Zibadi (Eds.), Chocolate in Health and Nutrition (cap. 1, pp. 3-9). New York: Humana Press. http://dx.doi.org/10.1007/978-161779-803-0_1

Crozier, S. J., Preston, A. G., Hurst, J. W., Payne, M. J., Mann, J., Hainly, L., \& Miller, D. L. (2011). Cacao seeds are a "Super Fruit": A comparative analysis of various fruit powders and products. 
Chemistry Central Journal, 5(1), 5. http://dx.doi.org/10.1186/1752153X-5-5. PMid:21299842

Cruz, M., Whitkus, R., Gómez-Pompa, A., \& Mota-Bravo, L. (1995). Origins of cacao cultivation. Nature, 375(6532), 542-543. http:// dx.doi.org/10.1038/375542a0.

d’El-Rei, J., Cunha, A. R., Burlá, A., Burlá, M., Oigman, W., Neves, M. F., Virdis, A., \& Medeiros, F. (2013). Characterisation of hypertensive patients with improved endothelial function after dark chocolate consumption. International Journal of Hypertension, 2013, 985087. http://dx.doi.org/10.1155/2013/985087. PMid:23533716.

Djoussé, L., Hopkins, P. N., North, K. E., Pankow, J. S., Arnett, D. K., \& Ellison, R. C. (2011). Chocolate consumption is inversely associated with prevalent coronary heart disease: the National Heart, Lung, and Blood Institute Family Heart Study. Clinical Nutrition (Edinburgh, Lothian), 30(2), 182-187. http://dx.doi.org/10.1016/j. clnu.2010.08.005. PMid:20858571

Engels, J. M. (1983). A systematic description of cacao clones. I. The discriminative value of quantitative characteristics. Euphytica, 32(2), 377-385. http://dx.doi.org/10.1007/BF00021446.

Food and Agriculture Organization - FAO. (2013). FAOSTAT Online Statistical Service. Retrieved from http://faostat.fao.org/.

Forsyth, W. G. C., \& Quesnel, V. C. (1957). Cacao glycosidase and colour changes during fermentation. Journal of the Science of Food and Agriculture, 8(9), 505-509. http://dx.doi.org/10.1002/jsfa.2740080902.

Frauendorfer, F., \& Schieberle, P. (2008). Changes in key aroma compounds of Criollo cocoa beans during roasting. Journal of Agricultural and Food Chemistry, 56(21), 10244-10251. http://dx.doi.org/10.1021/ jf802098f. PMid:18925740

García-Alamilla, P., Salgado-Cervantes, M. A., Barel, M., Berthomieu, G., Rodríguez-Jiménes, G. C., \& García-Alvarado, M. A. (2007). Moisture, acidity and temperature evolution during cacao drying. Journal of Food Engineering, 79(4), 1159-1165. http://dx.doi. org/10.1016/j.jfoodeng.2006.04.005.

International Organization for Standards - ISO. (1993). International Standard 8586-1: sensory analysis: general guidance for the selection, training and monitoring of assesors. Geneva.

Jinap, S., Dimick, P. S., \& Hollender, R. (1995). Flavour evaluation of chocolate formulated from cocoa beans from different countries. Food Control, 6(2), 105-110. http://dx.doi.org/10.1016/09567135(95)98914-M.

Lawless, H. T., \& Heymann, H. (1999). Sensory evaluation of foodprinciples and practices. Maryland: Aspen Publisher.

Macht, M., \& Dettmer, D. (2006). Everyday mood and emotions after eating a chocolate bar or an apple. Appetite, 46(3), 332-336. http:// dx.doi.org/10.1016/j.appet.2006.01.014. PMid:16546294

Melo, L. L. M. M., Bolini, H. M. A., \& Efraim, P. (2009). Sensory profile, acceptability, and their relationship for diabetic/reduced calorie chocolates. Food Quality and Preference, 20(2), 138-143. http:// dx.doi.org/10.1016/j.foodqual.2008.09.001.

Motilal, L., Zhang, D., Umaharan, P., Mischke, B. S., Mooleedhar, V., \& Meinhardt, L. W. (2010). The relic Criollo cacao in Belize genetic diversity and relationship with Trinitario and other cacao clones held in the International cocoa Genebank, Trinidad. Plant
Genetic Resources, 8(02), 106-115. http://dx.doi.org/10.1017/ S1479262109990232.

Quesnel, V. (1965). Agents inducing the death of the cacao seeds during fermentation. Journal of the Science of Food and Agriculture, 16(8), 441-447. http://dx.doi.org/10.1002/jsfa.2740160804.

Rodriguez-Campos, J., Escalona-Buendía, H., Orozco-Avila, I., LugoCervantes, E., \& Jaramillo-Flores, M. (2011). Dynamics of volatile and non-volatile compounds in cocoa (Theobroma cacao L.) during fermentation and drying processes using principal components analysis. Food Research International, 44(1), 250-258. http://dx.doi. org/10.1016/j.foodres.2010.10.028.

Serra-Bonvehí, J. (2005). Investigation of aromatic compounds in roasted cocoa powder. European Food Research and Technology, 221(1-2), 19-29. http://dx.doi.org/10.1007/s00217-005-1147-y.

Smith, N. (1999). The Amazon River Forest: a natural history of plants, animals, and people. New York: Oxford University Press.

Stark, T., Bareuther, S., \& Hofmann, T. (2006). Molecular definition of the taste of roasted cocoa nibs (Theobroma cacao) by means of quantitative studies and sensory experiments. Journal of Agricultural and Food Chemistry, 54(15), 5530-5539. http://dx.doi.org/10.1021/ jf0608726. PMid:16848542

Sukha, D. A., Butler, D. R., Umaharan, P., \& Boult, E. (2008). The use of an optimised organoleptic assessment protocol to describe and quantify different flavour attributes of cocoa liquors made from Ghana and Trinitario beans. European Food Research and Technology, 226(3), 405-413. http://dx.doi.org/10.1007/s00217-006-0551-2.

Sukha, D., \& Butler, D. (2005). The CFC/ICCO/INIAP Cocoa Flavour Project - Investigating the spectrum of fine flavour within genotypes and between origins. INGENIC Newsletter, 10, 22-25.

Thamke, I., Dürrschmid, K., \& Rohma, H. (2009). Sensory description of dark chocolates by consumers. LWT - Food Science and Technology, 42, 534-539. http://dx.doi.org/10.1016/j.lwt.2008.07.006.

Trognitz, B., Scheldeman, X., Hansel-Hohl, K., Kuant, A., Grebe, H., \& Hermann, M. (2011). Genetic population structure of cacao plantings within a young production area in Nicaragua. PLoS ONE, 6(1), e16056. http://dx.doi.org/10.1371/journal.pone.0016056. PMid:21264251

Vázquez-Ovando, J. A., Molina-Freaner, F., Nuñez-Farfán, J., BetancurAncona, D. \& Salvador-Figueroa, M. (2015). Classification of cacao beans (Theobroma cacao L.) of southern Mexico based on chemometric analysis with multivariate approach. European Food Research and Technology. 240(6), 1117-1128. http://dx.doi. org/10.1007/s00217-015-2415-0.

Vázquez-Ovando, J. A., Molina-Freaner, F., Nuñez-Farfán, J., OvandoMedina, I., \& Salvador-Figueroa, M. (2014). Genetic identification of Theobroma cacao L. trees with high Criollo ancestry in Soconusco, Chiapas, Mexico. Genetics and Molecular Research, 13(4), 10404-10414. http://dx.doi.org/10.4238/2014.December.12.2. PMid:25511024.

Voight, J. (2013). Chocolate and cocoa aroma. In R. Watson, V. R. Preedy \& S. Zibadi (Eds.), Chocolate in health and nutrition (cap. 7, pp. 89-101). New York: Humana Press. http://dx.doi.org/10.1007/9781-61779-803-0_7. 